\title{
Corrosion and Low Temperature Degradation of 3Y-TZP dental ceramics under acidic conditions
}

Published in the Journal of the European Ceramic Society (2020) vol. 40 (15) pp. 6114-6122 https://doi.org/10.1016/j.jeurceramsoc.2020.06.019

\author{
A. Nowicka ${ }^{\text {a }}$ H.F. El-Maghraby ${ }^{\text {abc }}$, A. Švančárkováad, D. Galuskováa \\ H. Reveron ${ }^{\mathrm{e}}$, L. Gremillard ${ }^{\mathrm{e}}$, J. Chevalier ${ }^{\mathrm{e}}$, D. Galusek ${ }^{\mathrm{ab}}$
}

\begin{abstract}
${ }^{a}$ FunGlass, Centre for Functional and Surface Functionalized Glass, Alexander Dubcek University of Trencin, Študentská 2, 911 50, Trenčín, Slovakia

b Joint Glass Centre of the IIC SAS, TnUAD and FChPT STU, Študentská 2, 911 50, Trenčín, Slovakia

${ }^{\mathrm{c}}$ Refractories, Ceramics, and Building Materials Department, National Research Centre, 33 El-Bohous St., 12622, Cairo, Egypt

${ }^{\mathrm{d}}$ Faculty of Chemical and Food Technology STU, Radlinského 9, 812 37, Bratislava, Slovakia

${ }^{\mathrm{e}}$ Université de Lyon, INSA-Lyon, MATEIS, UMR CNRS 5510, 20 Avenue Einstein, 69621 Villeurbanne, France
\end{abstract}

\begin{abstract}
$\underline{\text { Abstract }}$
Due to its excellent properties, yttria-stabilized tetragonal zirconia ceramics (Y-TZP) are considered to be an appropriate choice for advanced dental applications. However, the long-term surface stability of these materials in a humid environment is still a matter of discussion. In the present work, two commercial and one in-house prepared 3Y-TZP ceramics were studied. The materials stability and durability were evaluated in the light of their behavior against long-term corrosion under low acidic pH (up to 265 days) and Low Temperature Degradation (LTD). The extent of corrosion and LTD was monitored by determining the content of monoclinic zirconia at the surfaces by X-Ray Diffraction. The obtained results show that leaching of yttrium from the 3Y-TZP tested materials takes place. Nonetheless, there is no significant impact of yttrium loss on the vulnerability to LTD of corroded samples in the conditions of this work.
\end{abstract}

\section{Keywords :}

Accelerated aging tests ; Corrosion ; Dental ceramics ; Low Temperature Degradation (LTD) ; YTZP

\section{Introduction}

Yttria-stabilized tetragonal zirconia holds a unique place among dental ceramics because of its excellent mechanical properties, such as fracture toughness and high flexural strength. From an aesthetic point of view, yttria-stabilized tetragonal zirconia is white, often translucent and can be rather easily colored by the addition of trace rare earth elements [1,2]. To stabilize tetragonal $(t)$ $\mathrm{ZrO}_{2}$ at room temperature, $3 \mathrm{~mol} \%$ of $\mathrm{Y}_{2} \mathrm{O}_{3}$ is typically used [1]. Its excellent mechanical properties are the consequence of phase transformation toughening, which increases its crack propagation resistance [2]. 3Y-TZP ceramics can exhibit a bending strength of more than $1000 \mathrm{MPa}$, with toughness values being approximately $5-10 \mathrm{MPa} \cdot \mathrm{m}^{1 / 2}$ [3]. It can additionally be shaped by using CAD-CAM technology from pre-sintered blocks, which greatly facilitates its use as crowns or dental bridges [4]. Moreover, this material is considered an alternative to biomedical grade titanium for 
dental implants, in patients showing titanium hypersensitivity or allergic reactions $(0,06 \%$ for titanium dental implants [5]). However, it is well known that 3Y-TZP ceramics may be sensitive to Low Temperature Degradation (LTD or aging) when they are in contact with water. As a result of the LTD process, the tetragonal $(\mathrm{t})$ zirconia grains at the surface may transform spontaneously (i.e. without the need of an external applied stress) to the monoclinic phase (m) and the related volume expansion of 3-5\% results in surface roughening and the formation of microcracks [2]. It has been shown that LTD can occur at low temperatures such as human body or even ambient temperature [6]. LTD is thermally activated and the transformation rate is mainly controlled by the kinetics of surface reactions $[7,8]$. Material susceptibility to LTD depends on the degree of densification (more specifically the porosity), the stabilizer content and nature, the grain size, processing characteristics and the presence of residual stresses [9]. However, zirconia aging is still an open issue and to date, there is no full consensus on mechanisms and models to predict such effects. The most commonly accepted mechanism for LTD seems to be the annihilation of oxygen vacancies by water-derived species, which drives the $\mathrm{t} \rightarrow \mathrm{m}$ phase transformation. This process destabilizes the tetragonal phase and over stabilizes the monoclinic one [10,11]. On the other side, Lange et al. [12] proposed earlier a LTD mechanism based on the chemical reaction between $\mathrm{H}_{2} \mathrm{O}$ and yttria $\left(\mathrm{Y}_{2} \mathrm{O}_{3}\right)$. Further formation of the reaction product, $\mathrm{Y}(\mathrm{OH})_{3}$, leads to the depletion of the stabilizer (yttrium) from zirconia grains, which are then free to transform to the monoclinic phase [13]. Pandelon et al. [14] have suggested that yttrium is removed from the zirconia lattice and that its depletion takes place during the $\mathrm{t} \rightarrow \mathrm{m}$ transformation through aging zirconia in water vapor. It is to note that most of LTD experiments are conducted in water or in (water) steam at a $\mathrm{pH}$ of 7 . In the case of dental materials, the complexity of the oral environment should also be taken into account. The surfaces of these materials are exposed to different $\mathrm{pHs}$ which could be highly acidic $(\mathrm{pH}<3)$ due to e.g. the reflux of gastric fluid. In addition, the ingestion of beverages and food varies the $\mathrm{pH}$ of the buccal environment between 3-8. Moreover, the bacteria naturally present in the oral cavity are also highly effective in developing low $\mathrm{pH}$ conditions [15]. In addition to the $\mathrm{pH}$ diversity, the oral cavity is also exposed to important temperature changes. The maximum temperature recorded in the oral cavity during the consumption of hot beverages can reach $76.3^{\circ} \mathrm{C}[16]$ and the minimum is around $0{ }^{\circ} \mathrm{C}$ when iced drinks are taken [17]. All of these factors can substantially influence both the leaching of yttrium stabilizing ions $\left(\mathrm{Y}^{3+}\right)$ from zirconia-based dental restorations and their LTD.

For characterizing the chemical solubility of dental materials, the ISO 6872 standard recommends immersing samples in 4 vol.\% acetic acid (AcA) solutions for $16 \mathrm{~h}$ at $80^{\circ} \mathrm{C}$, which acts as a corrosive medium simulating an acidic $\mathrm{pH}$ comparable to that from juices and food [18]. The experiment performed by Milleding et al. [19] on the metal-ceramic porcelain, traditional allceramic porcelain, micro-leucite porcelain, glass-ceramic, and densely-sintered $99.7 \% \mathrm{Al}_{2} \mathrm{O}_{3}$ shows that a longer immersion time of $168 \mathrm{~h}$ in 4 vol.\% AcA could be used to simulate 22 years of immersion in artificial saliva at $22^{\circ} \mathrm{C}$. However, such a time-temperature equivalence may highly depend on the material tested and to the best of our knowledge, there are not published articles reporting on the evaluation of long term exposure of Y-TZP ceramics to acidic environments and its influence on yttrium depletion. Most published reports on 3Y-TZP subjected to corrosion in AcA, artificial saliva, or water vapor have been focused on the final mechanical behavior [20] and a limited amount of data is available on the influence of yttria depletion on the LTD of zirconia dental ceramics.

Therefore, in this work the long-term corrosion behavior of commercial and non-commercial 3YTZP ceramics was studied with the aim of determining if the loss of stabilizing $\mathrm{Y}^{3+}$ ions would be likely to trigger the $\mathrm{t} \rightarrow \mathrm{m}$ zirconia phase transformation and to elucidate whether corrosion in acidic aqueous environment can accelerate the process of aging and/or be by its nature fundamentally different from LTD. Hence, the influence of the loss of $\mathrm{Y}^{3+}$ ions during acidic corrosion on the LTD resistance of 3Y-TZP ceramics was also evaluated. 


\section{Materials and methods}

The study was conducted on commercially available and non-commercial 3Y-TZP ceramics prepared in the laboratory. Two different commercial materials were tested: IVOCLAR IPS e.max ${ }^{\circledR}$ ZirCAD (Ivoclar Vivadent, Schaan, Liechtenstein, hereafter referred as IVOCLAR) and DOCERAM Nacera ${ }^{\circledR}$ (DOCERAM Medical Ceramics, GmbH, Dortmund, Germany hereafter referred as DOCERAM). IVOCLAR pre-sintered blocks were cut with a diamond-cutting wheel (Buehler, Isomet 5000) to prepare platelets with dimensions of $10 \times 10 \times 2 \mathrm{~mm}^{3}$. The sintering was performed in air at $1450{ }^{\circ} \mathrm{C}-1 \mathrm{~h}$ with a heating rate of $10^{\circ} \mathrm{C} / \mathrm{min}$ and samples were polished down to $1 \mu \mathrm{m}$ using an automatic polishing machine and diamond suspensions (Buehler Ecomet 300). DOCERAM provided sintered pellets $(20 \mathrm{~mm}$ in diameter) already polished down to $1 \mu \mathrm{m}$. Noncommercial 3Y-TZP ceramics were also prepared in house from a hydrothermally synthesized powder. The raw materials used for the synthesis were zirconium oxychloride $\left(\mathrm{ZrOCl}_{2} \cdot 8 \mathrm{H}_{2} \mathrm{O}, 96\right.$ $\%$, BDH Chemicals Ltd, England), Yttrium oxide ( $\mathrm{Y}_{2} \mathrm{O}_{3}, 99.9 \%$, Fluka AG, Switzerland), ammonia solution, absolute ethyl alcohol and hydrochloric acid $\left(\mathrm{NH}_{4} \mathrm{OH} 33 \%, \mathrm{C}_{2} \mathrm{H}_{5} \mathrm{OH}\right.$ and $\mathrm{HCl}, 36.5-38.0$ \%supplied by El-Nasr Pharmaceutical Chemicals Co., Egypt). A precisely weighed amount of $\mathrm{ZrOCl}_{2} \cdot 8 \mathrm{H}_{2} \mathrm{O}$ was dissolved in a deionized water and mixed with a solution containing the desirable amount of stabilizer $\left(\mathrm{Y}_{2} \mathrm{O}_{3}\right.$ diluted in hydrochloric acid, $\left.\mathrm{HCl}, 1: 1\right)$ to ensure complete homogeneity of the solutions. Ammonia solution was added dropwise, while stirring, until the $\mathrm{pH}$ value reached 10 to form a gel. The Teflon reactor vessel containing the white gel with its mother liquid was transferred to a stainless-steel autoclave and was then hydrothermally treated at a temperature of $200{ }^{\circ} \mathrm{C}-2 \mathrm{~h}$. The hydrothermal treatment was carried out at $200^{\circ} \mathrm{C}-2 \mathrm{~h}$. Then, the autoclave was cooled down to room temperature using a cold-water stream, and the white settled precipitate was separated by filtration from the clear supernatant liquid. The sample was washed, first by boiled deionized water, then by absolute ethyl alcohol to remove the attached water from the hydrothermally prepared zirconia powders. After washing, the powders were $12 \mathrm{~h}$-aged in absolute ethyl alcohol, filtered, and then dried at $110^{\circ} \mathrm{C}$ for $24 \mathrm{~h}$. Then, powders were dispersed in water and freeze-dried (UNICRYO Freeze dryer MC2 $\times 2 \mathrm{~L}-60^{\circ} \mathrm{C}$, UNIEQUIP) to obtain granules with improved flowability. Pellets (10 $\mathrm{mm}$ diameter and $2 \mathrm{~mm}$ height) were uniaxially pressed (50 MPa) then cold iso-statically pressed (CIP) at $350 \mathrm{MPa}$. The as-prepared 3Y-TZP discs were debinded in two steps: $400{ }^{\circ} \mathrm{C}-0 \mathrm{~min}$ (heating rate: $10^{\circ} \mathrm{C} / \mathrm{h}$ ) and $800^{\circ} \mathrm{C}-30 \mathrm{~min}$ (heating rate: $120^{\circ} \mathrm{C} / \mathrm{h}$ ). Sintering was performed in air at $1500^{\circ} \mathrm{C}-2 \mathrm{~h}$ and samples were polished down to $1 \square \mathrm{m}$ in the same way described above (hereafter referred as $3 \mathrm{Y}-\mathrm{TZP}-1500$ ).

Sintered and polished samples were characterized by Scanning Electron Microscopy (SEM, Zeiss Supra55 VP). The composition of the investigated materials was determined by Energy Dispersive X-Ray Spectroscopy (EDS, JEOL JSM-7600). The densities of the materials were estimated by Archimedes' method by double weighting the samples in deionized water and in air. The mean grain size was determined by the linear intercept method [21] with the use of the Lince software (TU Darmstadt, Germany). The average intercept length was multiplied by the correction factor 1.56 to obtain the mean grain size.

Corrosion tests were carried-out in Teflon vessels using $5 \mathrm{~mL}$ of AcA $(\mathrm{pH}=2.4)$ solution. Commercial and non-commercial 3Y-TZP-1500 samples were completely covered by the solution and different temperatures and times were applied as shown in Table 1. The amount of ions leached from the materials (Y, Zr, $\mathrm{Al}$ and $\mathrm{Hf}$ ) to the corrosion solution was determined by Mass Spectrometry in Inductively Coupled Plasma (ICP-MS Agilent 7900) at times and temperatures also indicated in Table 1. The depth of material without stabilizing agent was also estimated assuming complete leaching of yttrium from the surfaces. 
Table 1. Experimental conditions for corrosion tests and LTD. Corroded + LTD samples are also indicated (highlighted).

\begin{tabular}{|c|c|c|c|c|}
\hline \multirow[b]{2}{*}{ Material } & \multicolumn{3}{|c|}{ Corrosion (AcA 4 vol.\%) } & \multirow{2}{*}{$\begin{array}{c}\text { LTD (water) } \\
134^{\circ} \mathrm{C}-2 \text { bar (time in hours and XRD } \\
\text { analysis points) }\end{array}$} \\
\hline & $\begin{array}{c}37^{\circ} \mathrm{C} \\
\text { (time in days) }\end{array}$ & $\begin{array}{c}60^{\circ} \mathrm{C} \\
\text { (time in days) }\end{array}$ & $\begin{array}{c}80{ }^{\circ} \mathrm{C} \\
\text { (time in days) }\end{array}$ & \\
\hline $\begin{array}{l}\text { IVOCLAR * } \\
\text { DOCERAM }\end{array}$ & $31,165,185,265 * *$ & $31,40,130 * *$ & $31,40,50$ & \multirow{2}{*}{$2,5,10,15,20,25,30$} \\
\hline $\begin{array}{c}\text { 3Y-TZP } \\
1500\end{array}$ & $10,20,40 * *$ & & & \\
\hline
\end{tabular}

*These samples were also corroded in water, $80{ }^{\circ} \mathrm{C}-40$ days + ICP-MS analysis (reference).

** At the end of corrosion tests, these samples were subjected to LTD, $134^{\circ} \mathrm{C}-2 \mathrm{bar}, 30 \mathrm{~h}$ (Corrosion $+\mathrm{LTD}-30 \mathrm{~h}$ ).

LTD tests were carried-out in steam at $134{ }^{\circ} \mathrm{C}$, under the absolute pressure of 3 bars in an autoclave (Sanoclav, type: LA-VA-MCS) at different times (2, 5, 10, 15, 20, 25 and $30 \mathrm{~h}$ ). In order to estimate the influence of yttrium leached during corrosion tests on the LTD behavior, accelerated aging tests (AAT, $134^{\circ} \mathrm{C}-2$ bars) were also performed on selected corroded specimens (see Table $1 .^{* *}$ ) using the same time points.

For ICP-MS analyses, the calibration solution was prepared from single element standards (ANALYTIKA, Prague, Czech Republic) with a concentration of $1000 \div 2 \mathrm{mg} \cdot \mathrm{L}^{-1}$ of $\mathrm{Y}, \mathrm{Zr}, \mathrm{Al}$ and Hf. Along with the testing of the corrosion solutions, analyses of blank solutions (test corrosion medium without any sample) were also carried out at the same times. The analyses of blank samples were carried out in order to correct the measured values of individual element concentrations with respect to the content of the elements present in the blank, not originating from 3Y-TZP ceramics. Additional corrosion tests in water at $80^{\circ} \mathrm{C}$ for 40 days were carried out for IVOCLAR and leaching solutions were also analyzed by ICP-MS. The concentration of leached ions $\left(Q_{i t}\right)$ was calculated according to the formula:

$$
Q_{i t}=\frac{\left(C_{i}-C_{\text {Blank }}\right) \times V}{S_{i}}\left[\mu \mathrm{g} / \mathrm{cm}^{2}\right]
$$

Where: $c_{i}$ - concentration of the element, $\left[\mathrm{g} / \mathrm{d} m^{3}\right], c_{\text {blank }}$ - concentration of the element in blank, $\left[\mu \mathrm{g} / \mathrm{d} m^{3}\right], V$-volume of the corrosion solution $\left[\mathrm{d} m^{3}\right], S$ - samples surface $\left[\mathrm{cm}^{2}\right]$.

The normalization $\left(N L_{\mathrm{it}}\right.$ of the concentration of the leached ion $\left(Q_{i t}\right)$ to its content in the material itself $\left(w_{i}\right)$ provides information on the dissolution of the material as a whole, or whether or not the preferential dissolution of any of the present phases, either crystalline or glassy, can be assessed [22].

$$
N L_{i t}=\frac{Q_{i t}}{w_{i}}\left[\mu \mathrm{g} / \mathrm{cm}^{2}\right]
$$

Where: $Q_{i t}$ - the concentration of leached ions $\left[\mu \mathrm{g} / \mathrm{cm}^{2}\right], w_{i}$ is the mass fraction of the element in the solid [wt. \%].

In this work, only the amount of yttrium ions leached from the material, $N L_{Y}$ was considered, because other elements leached from $3 \mathrm{Y}$-TZP specimens, i.e. $\mathrm{Zr}$, Sr, Hf were under the limit of detection of the experimental method $(0.03 \mu \mathrm{g} / \mathrm{L})$.

Assuming that the yttrium was homogeneously distributed in the sample and during corrosion the sample surface completely depleted, the depth of yttrium depletion $\left(H_{d e p}\right)$ can be calculated according to the formula: 


$$
H_{\text {dep }}=\frac{H_{S} \times S_{i} \times N L_{Y}}{w_{Y} \times m_{S}}[\mu m]
$$

Where: $H_{S}$ - sample height [m], $S_{i}$ - sample surface [ $\mathrm{m}^{2}$ ], $N L_{Y}$ - the normalized amount of yttrium ions leached from the material $\left[\mathrm{g} / \mathrm{m}^{2}\right], w_{Y}$ - the mass fraction of the yttrium in the solid [wt. \%], $m_{s}$ - sample mass $[\mu \mathrm{g}]$.

The leaching rates $\left(L_{\mathrm{r}}\right)$ at given temperatures were determined from the linear regression of the time dependence of the experimentally determined $N L_{Y}\left(\mu \mathrm{g} / \mathrm{cm}^{2}\right)$ values. Activation energies of dissolution were evaluated by plotting $\ln \left(L_{\mathrm{r}}\right)$ vs $1 / T$ according to the Arrhenius law.

The extent of corrosion and LTD was also analyzed in terms of the content of monoclinic phase (vol. \%) in 3Y-TZP ceramics and determined by X-Ray Diffraction analysis (XRD diffractometer, Panalytical Empyrean DY1098, $2 \theta=27^{\circ}-33^{\circ}$, using $C u K_{\alpha}$ radiation with a wavelength of $0.15405 \mathrm{~nm}$ ). Diffraction patterns were evaluated by the software HighScore Plus (v. 3.0.4.) with the crystallography open database COD 2018. The ICOD 04-002-2680 was selected for the zirconia tetragonal phase and the ICOD 04-002-5424 was selected for the monoclinic phase. The equation of Garvie and Nicholson was used to evaluate the relative amount of monoclinic zirconia $\left(X_{m}\right.$, wt.\%) [23]:

$$
X_{m}=\frac{I_{m}^{(11 \overline{1})}+I_{m}^{(111)}}{I_{m}^{(11 \overline{1})}+I_{m}^{(111)}+I_{i}^{(101)}}
$$

Where $\mathrm{I}_{\mathrm{x}}(h k l)$ designates the intensity of the peak corresponding to the plane $(h k l)$ for the monoclinic (m) and tetragonal (t) peaks.

The volume fraction of the monoclinic phase $\left(V_{m}\right)$ was evaluated from the empirical relationship established by Toraya [24]:

$$
V_{m}=\frac{1.311 \times X_{m}}{1+0.311 \times X_{m}}
$$

Aging kinetics were analyzed by the Mehl-Avhrami-Johnson (MAJ) equation [10]:

$$
V(t, T)=1-\exp \left(-(b \times t)^{n}\right)
$$

Where, $\mathrm{V}$ is the evolution of the monoclinic fraction $(\mathrm{V})$ versus time, $t$ is the duration of exposure to steam, $n$ is a constant known as a "MAJ exponent", which depends on both nucleation and growth kinetics of the transformation, and $b$ is a thermally activated parameter [25] that could be described by Arrhenius law. To determine all of the aging parameters a new procedure described by Gremillard et al. was used [26]. This procedure is based on the calculation of the global error function $\varepsilon$ between the measured values and the ones predicted by Eq. (7) by optimizing parameters $b_{0}, n$ and energy of activation for transformation $(Q)$.

$$
\varepsilon=\sum_{i} \frac{\sum_{j=1}^{N_{i}}\left(1-\exp \left[-\left(b_{0} \times \exp \left(\frac{-Q}{R T_{i}}\right) \times t_{j}\right)^{n}\right]-f_{i j}\right)^{2}}{N_{i}}
$$

Where $i$ is the number of temperatures tested and $j$, the number of time points for each temperature (for 1 temperature $T_{i}, N_{i}$ time points are measured), $f_{i j}$ is the measured monoclinic fraction at temperature $T_{i}$ and time $t_{j}$. Calculations of $b_{0}, n$ and $Q$ were conducted numerically by using a solver. 


\section{Results}

\subsection{Materials characterization}

Figure 1 shows the SEM micrographs of all tested materials after polishing. The results of statistical microstructural analysis are summarized in Table 2. In DOCERAM samples, polishing resulted in a visible $\mathrm{t} \rightarrow \mathrm{m}$ phase transformation at the surface (Figure $1 \mathrm{~b}$ ), reflected by the formation of characteristic martensitic relief [27].


Figure 1. Microstructures of all tested materials: a) IVOCLAR, b) DOCERAM, c) 3Y-TZP-1500. 


\begin{tabular}{ccccc}
\multicolumn{1}{c}{ Material } & \multicolumn{3}{c}{ IVOCLAR DOCERAM 3Y-TZP-1500 } \\
\hline \multirow{2}{*}{ Yttrium content $\left(\mathrm{Y}^{3+}\right)$} & [wt.\%] & $4.3 \pm 0.4$ & $4.6 \pm 0.8$ & $4.5 \pm 0.7$ \\
& {$[\mathbf{m o l \% ]}$} & $2.4 \pm 0.2$ & $2.6 \pm 0.4$ & $2.5 \pm 0.4$ \\
\hline \multirow{2}{*}{ Aluminum content $\left(\mathrm{Al}^{3+}\right)$} & {$[\mathbf{w t . \%}]$} & $0.1 \pm 0.03$ & $0.2 \pm 0.1$ & $0.2 \pm 0.1$ \\
& {$[\mathbf{m o l \% ]}$} & $0.2 \pm 0.06$ & $0.4 \pm 0.2$ & $0.4 \pm 0.2$ \\
\hline Sintering temperature and time [ $\left.{ }^{\circ} \mathbf{C - h}\right]$ & $1450-1$ & $1500-1$ & $1500-2$ \\
\hline \multicolumn{2}{c}{ Average grain size [nm] } & $590 \pm 78$ & $690 \pm 80$ & $482 \pm 46$ \\
\hline \multicolumn{2}{c}{ Relative density [\%] } & $97.8 \pm 0.3$ & $98.0 \pm 1.0$ & $97.0 \pm 1.0$ \\
\hline Monoclinic phase content after polishing [vol.\%] & $*$ & $2.5 \pm 0.1$ & $*$ \\
\hline
\end{tabular}

*Below the detection limit of XRD.

The presence of the monoclinic phase in polished DOCERAM specimens was confirmed by X-ray diffraction analysis $(2.5 \pm 0.1 \mathrm{vol}$. \%). A finer-grained microstructure was found in the in-house prepared material 3Y-TZP-1500 when compared to the commercial material DOCERAM, sintered under the same conditions of temperature. Unlike DOCERAM, no monoclinic phase was detected by XRD at the surface of IVOCLAR and 3Y-TZP-1500 materials (Table 2).

\subsection{Effect of acidic corrosion on $3 Y$-TZP ceramics}

The ICP-MS results after 40 days corrosion in AcA are shown in Table 3. Furthermore, all of the data measured by ICP-MS are given in Figure 2, Figure 3, Figure 4(a). Leaching of yttrium ions was observed for all tested materials and it was accelerated by increasing the temperature. However, the amount of yttrium leached from IVOCLAR, DOCERAM and 3Y-TZP-1500, even if significant, was relatively low.

Table 3. Concentration of yttrium ions (QY), normalized amounts of yttrium ions leached (NLY) and depth of yttrium depletion $\left(H_{\text {dep }}\right)$ from the tested materials after 40 days of corrosion in 4 vol\% AcA $(\mathrm{pH}=2.4)$. The last row represents results of yttrium ions leached from the IVOCLAR samples during the corrosion test in water (reference).

\begin{tabular}{|c|c|c|c|c|c|c|c|c|c|}
\hline \multirow[b]{2}{*}{$\begin{array}{l}\text { Temperature of } \\
\text { the experiment }\end{array}$} & \multicolumn{3}{|c|}{ IVOCLAR } & \multicolumn{3}{|c|}{ DOCERAM } & \multicolumn{3}{|c|}{ 3Y-TZP-1500 } \\
\hline & $\underset{\left[\mu \mathrm{g} / \mathrm{cm}^{2}\right]}{Q_{Y}}$ & $\begin{array}{c}N L_{Y} \\
{\left[\mu \mathrm{g} / \mathrm{cm}^{2}\right]}\end{array}$ & $\begin{array}{c}H_{d e p} \\
{[\mu \mathrm{m}]}\end{array}$ & $\underset{\left[\mu \mathrm{g} / \mathrm{cm}^{2}\right]}{Q_{Y}}$ & $\begin{array}{c}N L Y \\
{\left[\mu \mathrm{g} / \mathrm{cm}^{2}\right]}\end{array}$ & $\begin{array}{c}\boldsymbol{H}_{d e p} \\
{[\boldsymbol{\mu m}]}\end{array}$ & $\underset{\left[\mu \mathrm{g} / \mathrm{cm}^{2}\right]}{Q_{Y}}$ & $\begin{array}{c}N L Y \\
{\left[\mu \mathrm{g} / \mathrm{cm}^{2}\right]}\end{array}$ & $\begin{array}{c}H_{d e p} \\
{[\mu \mathrm{m}]}\end{array}$ \\
\hline $37^{\circ} \mathrm{C}$ & $0.18 \pm 0.03 *$ & $4.2 \pm 0.7 *$ & $0.11 *$ & $0.06 \pm 0.02 *$ & $1.3 \pm 0.5^{*}$ & $0.02 *$ & $0.4 \pm 0.09$ & $8.8 \pm 2.1$ & 0.35 \\
\hline $60^{\circ} \mathrm{C}$ & $0.34 \pm 0.02$ & $7.8 \pm 0.4$ & 0.21 & $0.10 \pm 0.02$ & $2.3 \pm 0.1$ & 0.08 & $0.35 \pm 0.04$ & $8.0 \pm 0.1$ & 0.32 \\
\hline $80^{\circ} \mathrm{C}$ & $0.90 \pm 0.38$ & $21 \pm 9$ & 0.57 & $0.64 \pm 0.27$ & $14 \pm 6$ & 0.46 & $1.10 \pm 0.31$ & $25 \pm 6$ & 0.97 \\
\hline $80^{\circ} \mathrm{C}$ (water) & $0.16 \pm 0.01$ & $3.8 \pm 1.5$ & 0.09 & N.M & N.M & N.M & N.M & N.M & N.M \\
\hline
\end{tabular}

N.M: not measured.

*In these samples, the duration of the test was 31 days, instead of 40 days. 
a)

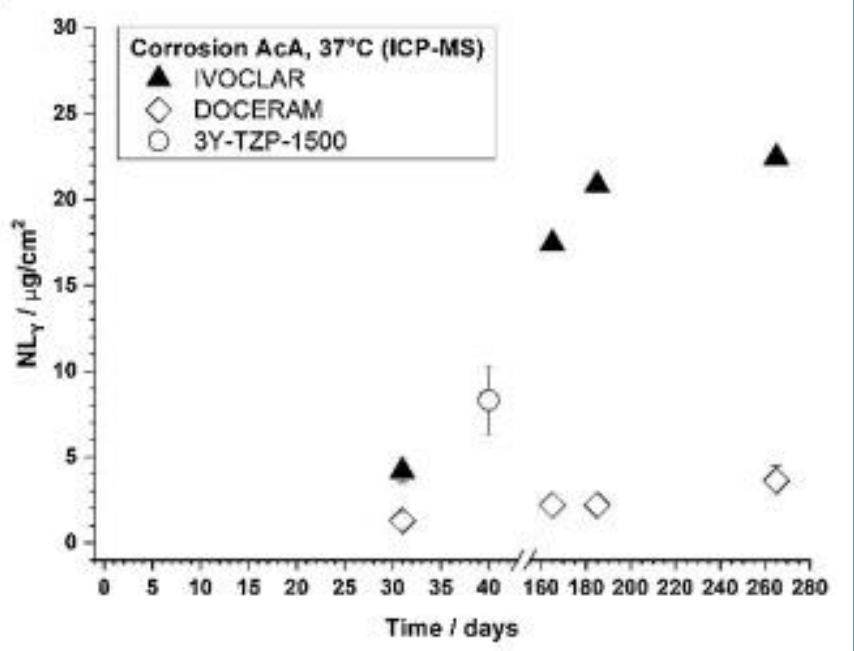

b)

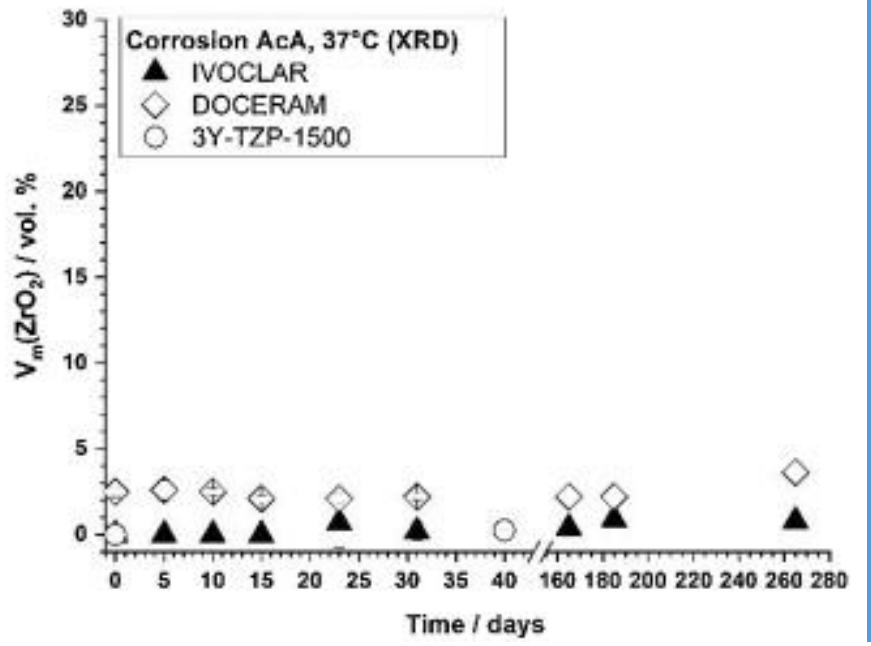

Figure 2. Corrosion test at $37^{\circ} \mathrm{C}$ in AcA as a function of time a) Normalized yttrium leaching NLy and b) Monoclinic phase content. 
a)

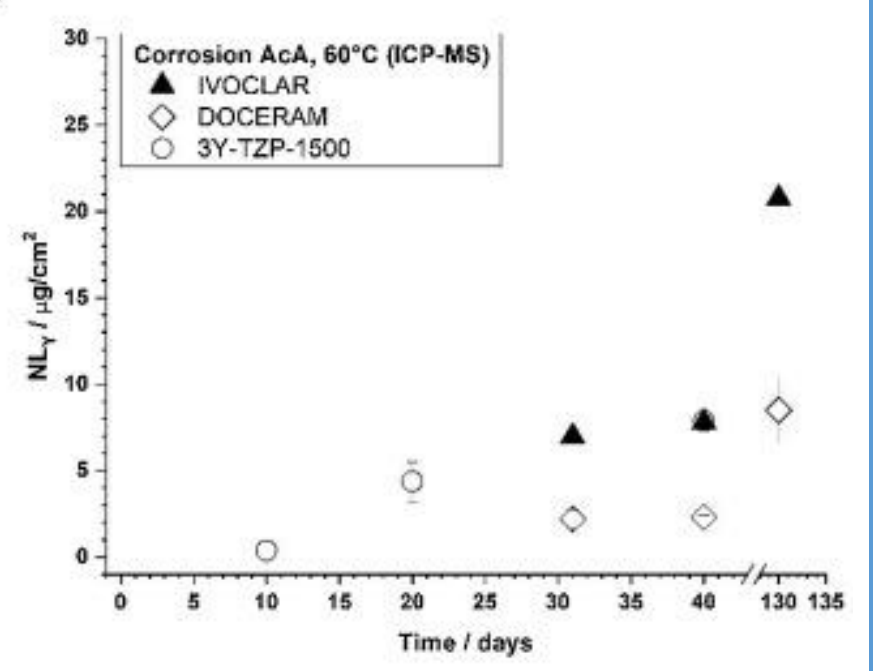

b)

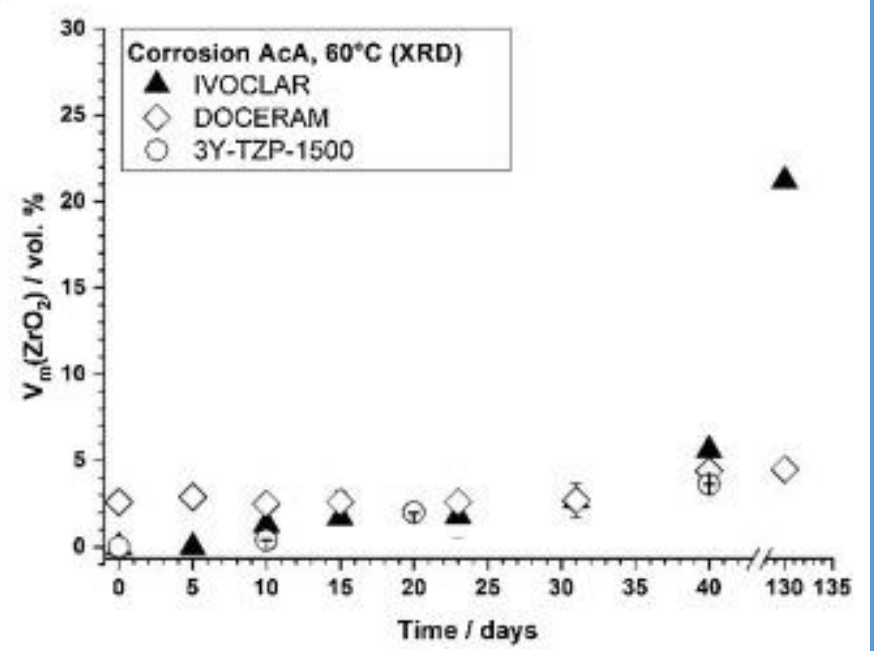

Figure 3. Corrosion test at $60^{\circ} \mathrm{C}$ in AcA as a function of time a) Normalized yttrium leaching NLy and $b$ ) Monoclinic phase content.

Over the course of the whole corrosion test, the yttrium leaching and the monoclinic phase content was monitored and the results are shown in Figure 2, Figure 3 and Figure 4 for different temperatures and times. As expected, with an increasing time of corrosion an increase in the amount of leached yttrium ions was observed (Figure $2 \mathrm{a}-4 \mathrm{a}$ ). In all tested samples, no measurable increase of the monoclinic phase content was detected at $37^{\circ} \mathrm{C}$ (Figure $2 \mathrm{~b}$ ). At $60^{\circ} \mathrm{C}$, the phase transformation was also negligible and any increase of the monoclinic phase content was in the range of the error of the measurement, except for IVOCLAR after 130 days of corrosion, in which the content of monoclinic phase reached 21 vol. \% (Figure $3 \mathrm{~b}$ ). Finally, a significant increase of monoclinic phase was observed in all materials after the corrosion test at $80^{\circ} \mathrm{C}$ (Figure $4 \mathrm{~b}$ ).

The commercial material DOCERAM (Figure 2, Figure 3, Figure 4) seems to be more resistant to yttrium depletion than IVOCLAR and 3Y-TZP-1500 during corrosion. However, there is no clear relationship between the zirconia transformation (content of monoclinic phase) and the amount of leached yttrium ions for the analyzed specimens (Figure 5). 
b)



a)
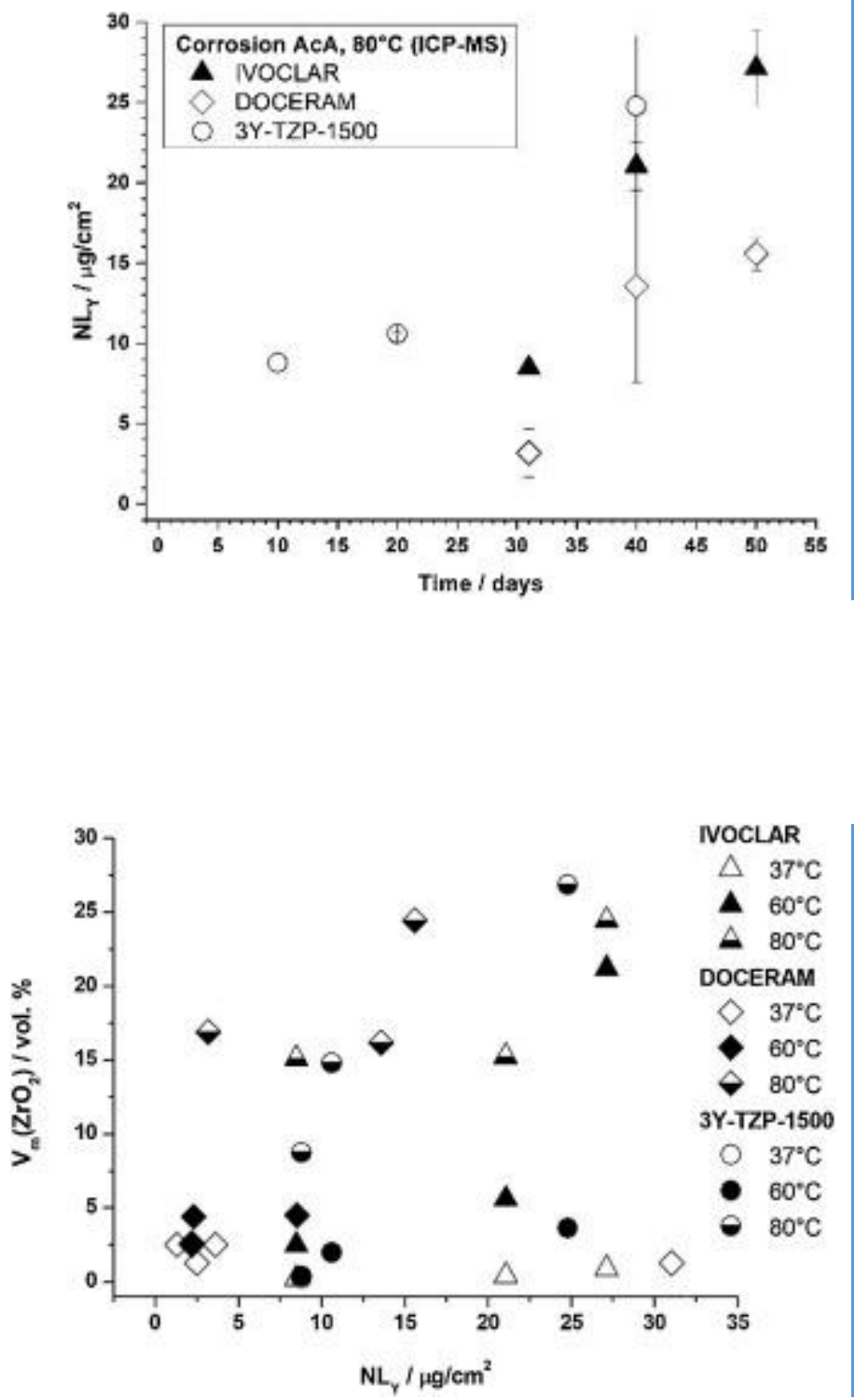

Figure 4. Corrosion test at $80^{\circ} \mathrm{C}$ in $\mathrm{AcA}$ as a function of time a) Normalized yttrium leaching NLy and $b$ ) Monoclinic phase content.
Figure 5. Content of monoclinic phase as a function of the normalized amount of leached yttrium ions after corrosion tests at different temperatures. 
IVOCLAR was also tested in deionized water at $80{ }^{\circ} \mathrm{C}$ as a reference medium. After 40 days of corrosion test in water, the content of the monoclinic phase reached $11.0 \mathrm{vol} . \%$. The transformation was at the same order of magnitude obtained during the corrosion in AcA where the monoclinic phase content was $16.2 \mathrm{vol} . \%$, even if the quantity of yttrium leached was more than 3 times lower (see Table 3) corroborating the absence of correlation between yttrium leaching extent and zirconia phase transformation.

The leaching rates $\left(L_{\mathrm{r}}\right)$ at given temperatures are shown in Table 4. The Arrhenius plot of yttrium dissolution rate $\ln \left(L_{r}\right)$ vs $1 / T$ is shown in Figure 6 . The estimation of the energies of activation was possible only for DOCERAM $(88 \pm 12 \mathrm{~kJ} / \mathrm{mol})$ and IVOCLAR $(51 \pm 21 \mathrm{~kJ} / \mathrm{mol})$.

Table 4. Yttrium leaching rates during corrosion tests at different temperatures.

\begin{tabular}{|c|c|c|c|}
\hline Temperature $\left({ }^{\circ} \mathbf{C}\right)$ & $\operatorname{IVOCLAR}\left(\mu \mathrm{g} \cdot \mathbf{c m}^{-2} \cdot \mathbf{h}^{-1}\right)$ & $\operatorname{DOCERAM}\left(\mu \mathrm{g} \cdot \mathrm{cm}^{-2} \cdot \mathbf{h}^{-1}\right)$ & 3Y-TZP-1500 $\left(\mu \mathrm{g} \cdot \mathrm{cm}^{-2} \cdot \mathrm{h}^{-1}\right)$ \\
\hline 37 & $3.4 \cdot 10^{-3}$ & $4.0 \cdot 10^{-4}$ & N.M \\
\hline 60 & $5.9 \cdot 10^{-3}$ & $2.8 \cdot 10^{-3}$ & $1.1 \cdot 10^{-2}$ \\
\hline 80 & $4.1 \cdot 10^{-2}$ & $2.7 \cdot 10^{-2}$ & $2.1 \cdot 10^{-2}$ \\
\hline
\end{tabular}

N.M: not measured.

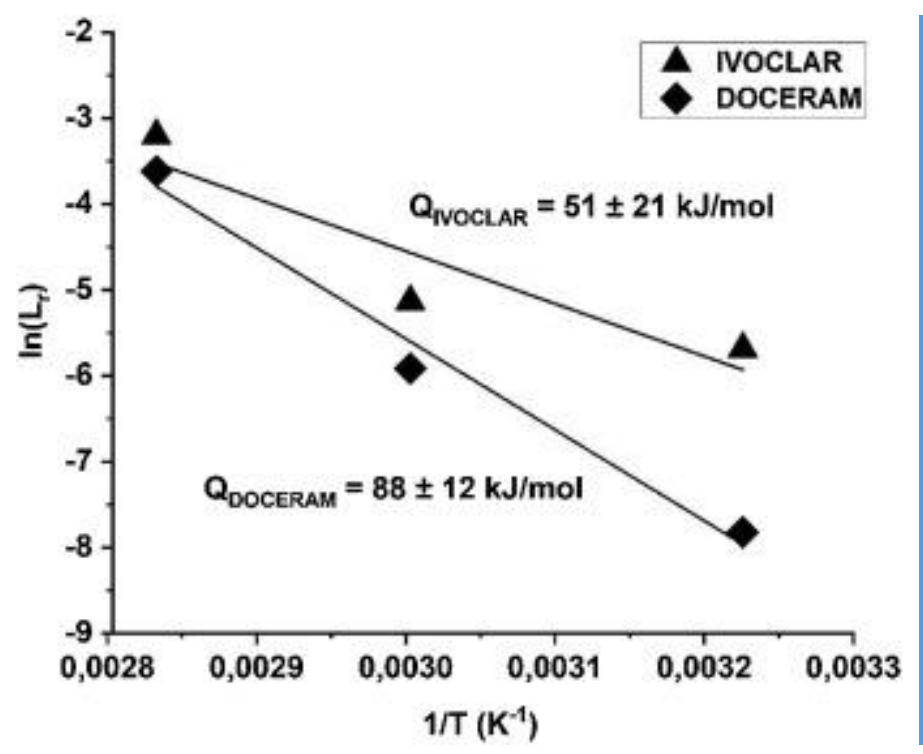

Figure 6. Yttrium leaching rates vs. temperature of corrosion for DOCERAM and IVOCLAR samples and calculated activation energies.

\subsection{LTD and the influence of yttrium ions leaching during corrosion on LTD}

Figure 7 summarizes the experimental results of tests performed in water-steam at $134{ }^{\circ} \mathrm{C}$ for up to $30 \mathrm{~h}$. It is noticeable that $3 \mathrm{Y}$-TZP-1500 and IVOCLAR samples aged much faster than DOCERAM, in which the monoclinic phase content after $30 \mathrm{~h}$ of aging was about 4 times lower. 


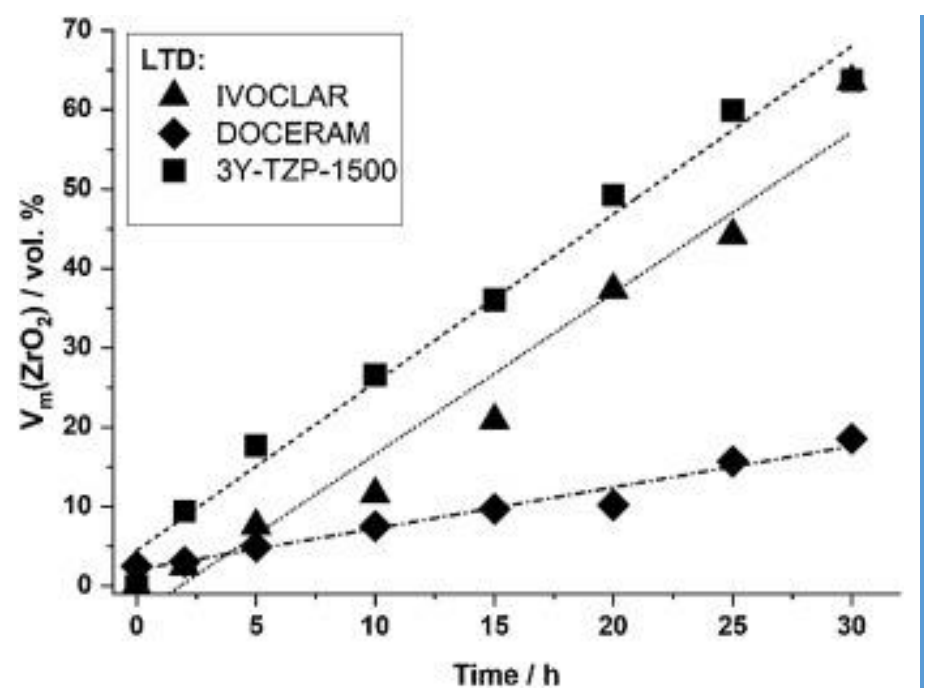

Figure 7. Content of monoclinic phase on $3 Y$-TZP samples after $A A T$ at $134^{\circ} \mathrm{C}$.

The best fit of the aging kinetics for IVOCLAR and 3Y-TZP-1500 samples gave values summarized in Table 5. Since the content of the monoclinic phase was relatively low after $30 \mathrm{~h}$, the determination of the aging parameters for DOCERAM was not possible.

Table 5. Parameters for aging (LTD) in the case of IVOCLAR and 3Y-TZP-1500 specimens.

\begin{tabular}{cccc} 
Parameters for aging kinetics & IVOCLAR & 3Y-TZP-1500 \\
\hline $\boldsymbol{V}_{\boldsymbol{M}}$ & & 0.80 & 0.77 \\
$\boldsymbol{b}_{\boldsymbol{0}}$ & & $1.14 \times 10^{10}$ & $7.53 \times 10^{11}$ \\
$\boldsymbol{Q}(\mathbf{k J} / \mathbf{m o l})$ & & 89.3 & 102.5 \\
& $\mathbf{3 7}^{\circ} \mathbf{C}$ & $1.01 \times 10^{-5}$ & $3.89 \times 10^{-6}$ \\
$b$ at given temperature & $\mathbf{6 0}^{\circ} \mathbf{C}$ & $1.10 \times 10^{-4}$ & $6.08 \times 10^{-5}$ \\
& $\mathbf{8 0}^{\circ} \mathbf{C}$ & $6.86 \times 10^{-4}$ & $4.96 \times 10^{-4}$ \\
$\boldsymbol{n}$ & $\mathbf{1 3 4}^{\circ} \mathbf{C}$ & $3.89 \times 10^{-2}$ & $5.12 \times 10^{-2}$ \\
Overall error & & 2.2 & 1.1 \\
\hline
\end{tabular}

From the aging parameters obtained after AAT at $134{ }^{\circ} \mathrm{C}$ which are reported in Table 5 is then possible to predict the evolution of $\mathrm{t}-\mathrm{m}$ phase transformation due to LTD at different temperatures in order to compare the experimental points obtained from corrosion tests at 37,60 and $80{ }^{\circ} \mathrm{C}$ with the predicted or fitted one from LTD data. Figure 8 shows the dependencies of experimental (symbols) and fitted (lines) monoclinic phase fractions at temperatures ranging from $37{ }^{\circ} \mathrm{C}$ to $134{ }^{\circ} \mathrm{C}$ for IVOCLAR and 3Y-TZP-1500 samples. The measured monoclinic phase contents in the initial stages and at longer corrosion times fitted well to the calculated kinetics (lines), considering extrapolation from LTD data in water-steam. 
a)



b)

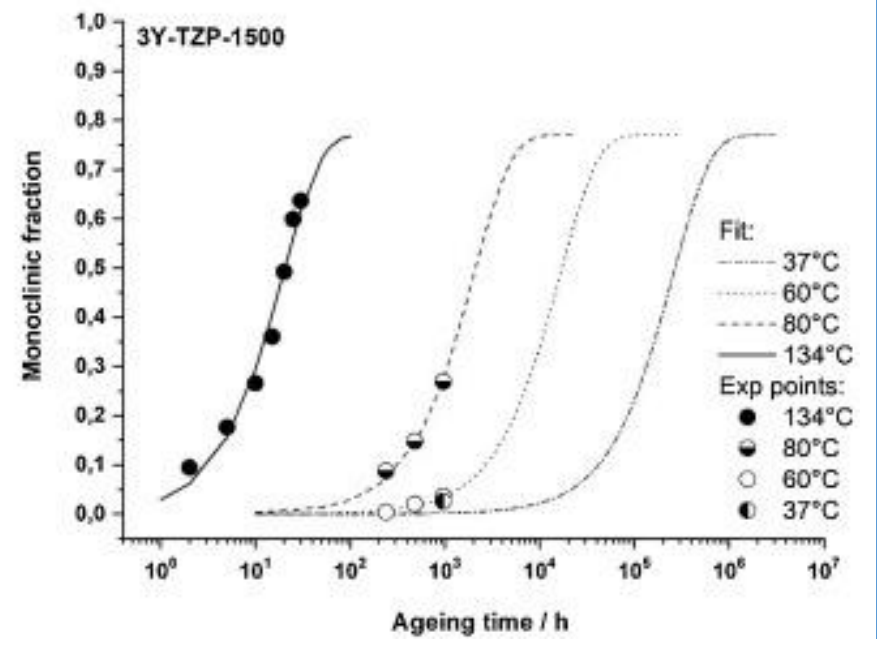

Figure 8. Aging kinetics of a) IVOCLAR and b) $3 Y$ TZP-1500; experimental data points are represented by symbols and calculated kinetics are shown as lines.

Figure 9 summarizes the contents of monoclinic zirconia in both previously corroded and noncorroded samples after the AAT (Table 1. **). Data obtained from AAT of corroded samples were corrected in accordance with the previous estimations obtained from the MAJ equation. For example, the corrosion of IVOCLAR in AcA at $37^{\circ} \mathrm{C}$ for 265 days, corresponds to $0.6 \mathrm{~h}$ (about $40 \mathrm{~min}$ ) of AAT at $134^{\circ} \mathrm{C}$. Therefore, each time interval of the AAT for corroded IVOCLAR specimens at $37^{\circ} \mathrm{C}$ for 265 days was shifted by $0.6 \mathrm{~h}$. Similar corrections have been introduced for each corroded sample. The corrected data did not show any difference between previously corroded and uncorroded samples in terms of transformability. The contents of monoclinic zirconia in both the uncorroded ceramics and in the ceramics corroded at $37^{\circ} \mathrm{C}, 60^{\circ} \mathrm{C}$ and $80{ }^{\circ} \mathrm{C}$ prior to AAT were almost the same. Furthermore, the estimated lifetime of tested materials under the conditions typical in the oral cavity (i.e. the time in which the transformation will reach the maximum value at $37^{\circ} \mathrm{C}$ ) is then as follows: IVOCLAR: 14 years, 3Y-TZP-1500: 46 years. 
b)

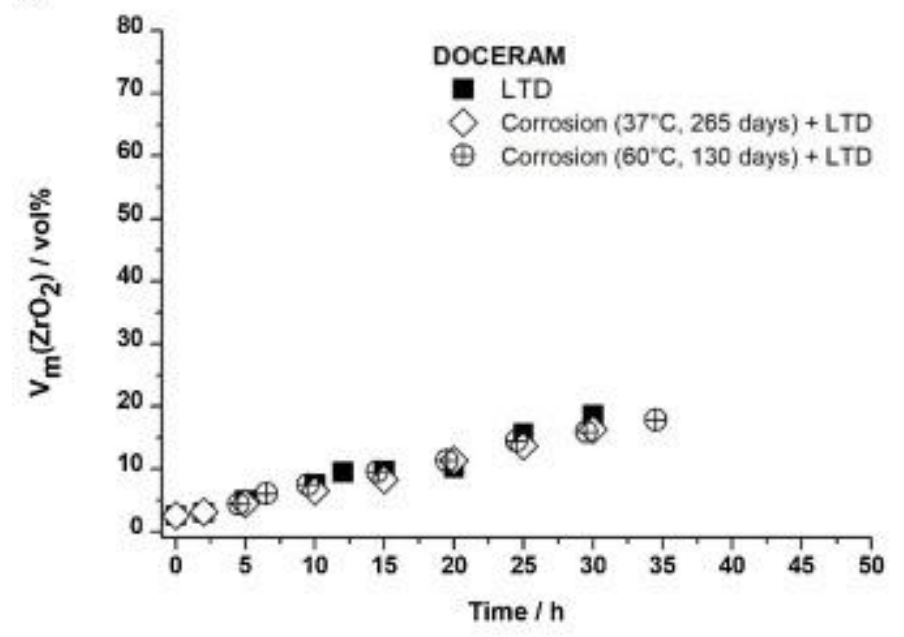

a)

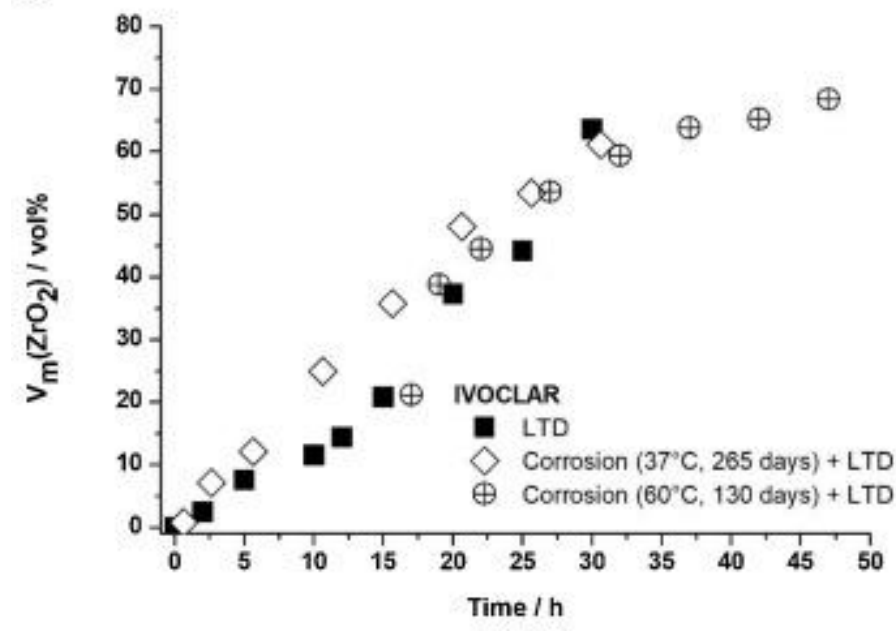

c)

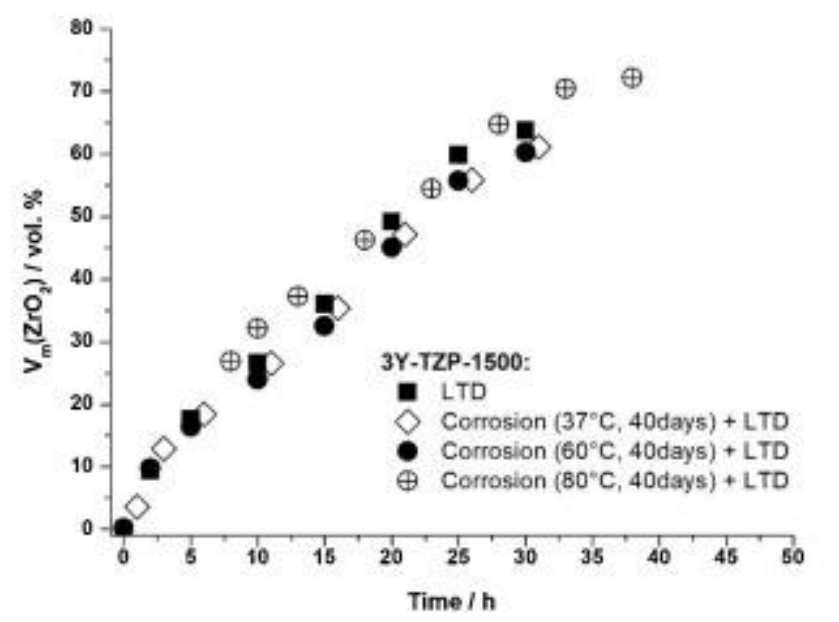

Figure 9. Monoclinic content comparison between samples after LTD and samples previously corroded within times and temperature summarized in Table 1 (**) then subjected to LTD for: a) IVOCLAR, $b$ ) DOCERAM, c) $3 Y-T Z P-1500$.

\section{Discussion}

The results of this study show that the susceptibility to corrosion and low-temperature degradation (LTD) was different from a 3Y-TZP to another. Materials were quite similar in density (97-98\% of the theoretical density), microstructure (mean grain size 0.5 to $0.7 \square \mathrm{m}$ ), sintering temperature 
$\left(1450-1500{ }^{\circ} \mathrm{C}\right.$ for 1 or $2 \mathrm{~h}$ ) and were all polished. However, the amount of yttrium leaching and the extent of LTD was significantly different. Moreover, there was no correlation between ion leaching and monoclinic content after aging.

Considering LTD, the content of monoclinic phase increased with aging time, in agreement with other published studies $[28,29,30]$. The commercial ceramic DOCERAM was found to be the densest $(97.8 \%)$ and resistant to corrosion and LTD, despite the fact that its average grain size was the largest from all tested ceramics (Table 2). Lughi and Sergo, in their review [1], summarized the influence of the grain size on LTD. They concluded that reducing the average grain size in zirconiabased ceramics did not always have a beneficial effect, and the role of the grain size in LTD was interlinked with the presence of chemical stabilizers or stresses. In addition, different surface features led to highly different aging kinetics [31]. Literature has demonstrated that compressive residual stresses are produced by the $\mathrm{t}-\mathrm{m}$ phase transformation during surface polishing, because of the impossibility of accommodating the shape changes of the variants constrained by the surrounding non-transformed material [32]. These compressive residual stresses due to surface finishing may oppose the grain volume increase during the $\mathrm{t}-\mathrm{m}$ transformation, and thus delay or suppress aging [33]. Deville et al. [34] described that the formation of a thin layer of compressive residual stress protects the surface against new phase transformation. The formation of this compressive residual stress layer may decrease the susceptibility of Y-TZP to LTD [35]. According to Deville et al. [34] residual stresses could arise from the elastic/plastic damage at the ceramic surface induced by the diamond grains during polishing [36]. The magnitude of such tensile stresses can change the stability of the zirconia grains, and the propensity to transform during aging treatments. The fact that the DOCERAM samples were polished by the company, with a different protocol leading to an already transformed zone under compression, may explain the different aging rate. Polished DOCERAM samples contained already $2.5 \%$ of monoclinic phase and typical transformation patterns on surface grains (see Figure 1) prior to aging/corrosion tests: the presence of the monoclinic phase could thus generate compressive residual stress layer, decreasing susceptibility of the materials to LTD and AcA. Results thus underline again the effect of surface preparation on aging kinetics.

A small addition of alumina can also influence degradation of Y-TZP ceramics. According to Zhang et al. [37], $\mathrm{Al}^{3+}$ dissolved and segregated at the zirconia grain boundaries effectively contributed to the improved degradation resistance. Their results show that the solubility of alumina in tetragonal zirconia increases with decreasing yttria content and increasing sintering temperature. The degradation resistance of $3 \mathrm{Y}-\mathrm{TZP}$ ceramics increased as the amount of alumina addition increased from 0 to $0.25 \mathrm{wt} . \%$. As shown in Table 2 , all materials tested in this study contained small amounts of aluminum, $0.1 \mathrm{wt} \%$ in IVOCLAR, and $0.2 \mathrm{wt} \%$ in DOCERAM and in the in-house prepared zirconia ceramics sintered at $1500^{\circ} \mathrm{C}$. Even if present in all materials of the present study, a different content may also be an additional factor contributing to different aging kinetics.

All in all, the present results confirm the fact that 3Y-TZP ceramics may behave highly different, while presenting quite similar microstructural features. Subtle changes in compositions, sintering conditions and final surface finish may significantly affect LTD kinetics.

Considering corrosion tests, the study in the acidic environment was performed to investigate the leaching of $\mathrm{Y}^{3+}$ and its potential influence on the tetragonal to monoclinic phase transformation. It was hypothesized that the acidic, aqueous environment provided by the AcA might accelerate the process of aging. Examination of the aqueous solution and its effect on ion leaching from the $3 \mathrm{Y}$ TZP surface indicated that the loss of stabilizing ions is increasing with time and temperature (see Figure 2). Furthermore, the acidic environment is much more aggressive than a neutral $\mathrm{pH}$ environment and it accelerates the dissolution of yttrium ions from the material. However, when testing the impact of the acidic environment at $80^{\circ} \mathrm{C}$ on phase transformation we found that the 
extent of phase transformation was similar to that obtained from the test in distilled water under the same conditions (IVOCLAR sample). This behavior indicates that the loss of yttrium ions seems to have limited impact on the zirconia phase transformation. This was confirmed by further studies of accelerating aging of specimens previously corroded in AcA under different time-temperature regimes (see Figure 9). Our conclusion is that some depletion of yttrium ions occurs during the process of corrosion and aging, which was also observed by Pandoleon et al. [14], but at least in the conditions or this work, it does not accelerate $\mathrm{t}-\mathrm{m}$ transformation during LTD tests. Already, Yoshimura et al. [38] stated in 1987 that the formation of $\mathrm{Y}(\mathrm{OH})_{3}$ and yttrium depletion cannot be considered as an essential mechanism of the nucleation of the $t-m$ transformation. The depth of yttria leaching estimated in this work is quite small and consistent with the diffusion coefficient of yttrium which would be extremely low at the $\mathrm{T}^{\circ}$ of the test. In other words, the extent (depth) of $\mathrm{Y}^{3+}$ ion leaching is not sufficient to trigger aging. The rate of water-radical diffusion, which acts to destabilize the t-phase, is higher than the diffusion (depletion) of yttria and plays the major role.

Aqueous environment and temperatures higher than $60{ }^{\circ} \mathrm{C}$ are accelerating the phase transformation in $3 \mathrm{Y}$-TZP ceramics. The most reasonable mechanism for phase transformation is the diffusion of water derived species which leads to a progressive change of the stability of the tetragonal grains, accompanied by the volume increase resulting in a surface uplift and large stresses that can provoke the creation of cracks along the grain boundaries, as proposed by Chevalier et al. [39]. Unfortunately, there is a lack of data in available literature related to the influence of acidic media on zirconia-based dental ceramics for yttrium dissolution. Obtained data therefore could not be compared to other scientific works.

Taking into account that leaching of yttrium from the commercial materials was observed, it is worth considering its toxicity. The study on rats conducted by Wang et. al [40] found no adverse effect of $29.1 \mathrm{mg} / \mathrm{kg}$ of body weight per day of yttrium administered orally in the form of soluble yttrium nitrate for 90 days. The amounts of yttrium leached from dental implants (of the order of magnitude of $310^{-9} \mathrm{mg} / \mathrm{kg} / \mathrm{day}$ measured here in the worst case) can be thus considered far below the amounts that might affect human health.

Calculated prediction of the monoclinic phase development by the stepwise procedure provided good information on the possible transformation mechanism, which fitted quite well to experimental points [41]. However results could be improved by testing the specimens at various temperatures where difference between them is much lower compared to temperature ranges already used in our experiments. Because of the excellent agreement between corrosion experimental data and the aging kinetics estimated from the MAJ equation (LTD at $134{ }^{\circ} \mathrm{C}$ ), we can deduce that the acidic corrosion process was controlled by the same mechanism(s) as low temperature degradation (LTD). The calculated activation energy values obtained in our work are in the range $89-102 \mathrm{~kJ} / \mathrm{mol}$, which is close to those reported in the literature $[5,10,24]$. Our study indicates that the activation energy of transformation differs in various tested materials. However, the ISO standard assumes the activation energy of transformation to be approximately the same for all stabilized zirconia ceramics. This assumption may lead to the wrong estimation of the material resistance to LTD. Our results comply with the conclusion of Zhang et.al [41] who stated the following: "the commonly used statement ( 1 h of autoclave treatment at $134^{\circ} \mathrm{C}$ has theoretically the same effect as 3-4 years in vivo at $37^{\circ} \mathrm{C}$ ) cannot be generalized for all Y-TZP ceramics, and it is necessary for each specific zirconia-based ceramic to calculate the activation energy in order to extrapolate the aging kinetics to the body temperature". Chevalier et al. [42] also concluded that the MAJ theory is not a universal law for all zirconia-containing materials, but it is only a tool for rationalizing the individual environmental behavior of each particular ceramic composition and microstructure. 


\section{$\underline{\text { 5. Conclusions }}$}

The corrosion in 4 vol.\% AcA of all tested 3Y-TZP ceramics results in leaching of stabilizing yttrium ions. The acidity of the medium seems to accelerate this process. However, under the experimental conditions here implemented, yttrium losses resulting from the corrosion phenomenon cannot be correlated with the extent of $\mathrm{t}-\mathrm{m}$ zirconia phase transformation. Moreover, the kinetic of low-temperature degradation is not affected by this loss of yttrium and thereby the content of the monoclinic phase at the corroded surfaces, in other words yttrium leaching does not trigger LTD.

\section{Declaration of Competing Interest}

The authors declare that they have no known competing financial interests or personal relationships that could have appeared to influence the work reported in this paper.

\section{$\underline{\text { Acknowledgments }}$}

The authors would like to acknowledge European Ceramic Society funding under the JECS TRUST APPLICATION (grant contract No 201598). Furthermore, the financial support of this work by the APVV grant contract no. SK-FR-2017-0008 and the project Centre for Functional and Surface Functionalized Glass (CEGLASS), ITMS code is 313011R453, operational program Research and innovation, co-funded from European Regional Development Fundis gratefully acknowledged.

\section{$\underline{\text { References }}$}

1. V. Lughi, V. Sergo, Low temperature degradation - aging - of zirconia: a critical review of the relevant aspects in dentistry, Dent. Mater., 26 (2010), pp. 807-820

2. J. Chevalier, J. Loh, L. Gremillard, S. Meille, E. Adolfson, Low - temperature degradation in zirconia with a porous surface, Acta Biomater., 7 (2011), pp. 2986-2993

3. J. Chevalier, L. Gremillard, S. Deville, Low-temperature degradation of zirconia and implications for biomedical implants, Annu. Rev. Mater. Res. (2007), pp. 1-32

4. Ch. Ritzberger, E. Apel, W. Holand, A. Peschke, V.M. Rheiberger, Properties and clinical application of three types of dental glass-ceramics and ceramics for CAD-CAM technologies, Materials (2010), pp. 3700-3713

5. A.Sicilia, S. Cuesta, G. Coma, I. Arregui, C. Guisasola, E. Ruiz, A. Maestro, Titanium allergy in dental implant patients: a clinical study on 1500 consecutive patients, Clin. Oral Implants Res. (2008), pp. 823-855

6. J. Cotič, P. Jevnikar, A. Kocjan, T. Kosmač, Complexity of the relationships between the sintering-temperature-denpendent grain size, airborne-particle abrasion, ageing and strength of 3Y-TZP ceramics, Dent. Mater., 32 (2016), pp. 510-518

7. J. Chevalier, Low-temperature aging of Y-TZP ceramics, J. Am. Ceram. Soc., 82 (1990), pp. 2150-2154

8. T. Sato, S. Ohtaki, M. Shimada, Transformation of yttria partially stabilized zirconia by low temperature annealing in air, J. Mater. Sci., 20 (1985), pp. 1466-1470

9. G.K.R. Pereira, T. Silvestri, R. Camargo, M.P. Rippe, M. Amaral, C.J. Kleverlaan, L.F. Valandro, Mechanical behavior of a Y-TZP ceramic for monolithic restorations: effect of griding and low-temperature aging, Mater. Sci. Eng. C, 63 (2016), pp. 70-77 
10. C. Wei, L. Gremillard, Toward the prediciton of hydrothermal aging of 3Y-TZP bioceramics from processing parameters, Acta Mater. (2018), pp. 245-256

11. X. Guo, Hydrothermal degradation mechanism of tetragonal zirconia, J. Mater. Sci. (2001), pp. 3737-3744

12. F.F. Lange, G.L. Dunlop, B.I. Davis, Degradation during aging of transformationtoughened $\mathrm{ZrO2}-\mathrm{Y} 2 \mathrm{O3}$ materials at $\mathbf{2 5 0}^{\circ} \mathrm{C}$, J. Am. Ceram. Soc., 69 (1986), pp. 237-240

13. S. Lawson, Environmental degradation of zirconia ceramics, J. Eur. Ceram. Soc., 15 (1995), pp. 485-502

14. P. Pandoleon, E. Kontonasaki, N. Kantiranis, N. Pliatsikas, P. Patsala, L. Papadopoulou, T. Zorba, K.M. Paraskevopoulo, P. Koidis, Aging of 3Y-TZP dental zirconia and yttrium depletion, Dent. Mater. (2017), pp. 385-392

15. M.V. Swain, Impact of oral fluids on dental ceramics: What is the clinical relevalence? Dent. Mater., 30 (2014), pp. 33-42

16. O. Feuerestein, K. Zeichner, C. Imbari, Z. Ormianer, N. Samet, El. Weiss, Temperature changes in dental implants following exposure to hot substances in an ex vivo model, Clin. Oral Implants Res., 19 (2008), pp. 629-633

17. C.W. Barclazy, D. Spence, W.R.E. Laird, Intra-oral temperatures during function, J. Oral Rehabil. (2005), pp. 886-894

18. B. Kukattrakoon, Ch. Hengtrakool, U. Kedjarune-Leggat, The effect of acidic agents on surface ion leaching and surface characteristics od dental porcelains, J. Prosthet. Dent. (2010), pp. 148-162

19. P. Milleding, A. Wennerberg, S. Akaeddin, S. Karlsson, E. Simon, Surface corrosion of dental ceramics in vitro, Biomaterials (1990), pp. 733-746

20. S. Ban, H. Sato, Y. Suehiro, H. Nakanishi, M. Nawa, Biaxial flexure strength and low temperature degradation od Ce-TZP/Al203 nanocomposite and Y-TZP as denatal restoratives, J. Biomed. Mater. Res. Part B Appl. Biomater., 87 (2) (2008), pp. 492-498

21. J.-H. Han, D.-Y. Kim, Determination of threedimensional grain size distribution by linear intercept measurement, Acta Mater. (1998), pp. 2021-2028

22. D. Galuskova, M. Kasiarova, M. Hnatko, D. Galusek, P. Sajgalik, J. Dusza, The influence of corrosion in an aqueous solution of $\mathrm{NaCl}$ on fracture and strength of various structural ceramics, Key Eng. Mater., 409 (2009), pp. 260-266

23. R.C. Garvie, P.S. Nicholson, Phase analysis in zirconia systems, J. Am. Ceram. Soc., 55 (1972), pp. 303-305

24. H. Toraya, M. Yoshimura, S. Somiya, Calibration curve for quantitative analysis of the monoclinic-tetragonal ZrO2 system by x-ray diffraction, J. Am. Ceram. Soc., 67 (1984), pp. $119-121$

25. C. Wei, L. Gremillard, Surface treatment methods for mitigation of hydrothermal ageing of zirconia, J. Eur. Ceram. Soc., 39 (14) (2019), pp. 4322-4329

26. L. Gremillard, C. wei, J. Chevalier, K. Hans, T. Oberbach, A fast, stepwise procedure to assess time-temperature equivalence for hydrothermal ageing of zirconia-based materials, J. Eur. Ceram. Soc., 38 (2018), pp. 181-186

27. S. Deville, G. Guenin, J. Chevalier, Martensitic transformation in zirconia part II. Martensite growth, Acta Mater., 52 (2004), pp. 5709-5721

28. R. E.Camposilvan, L. Leone, R. Gremillard, Sorrentino, F. Zarone, M. Ferrari, J. Chevalier, Aging resistance, mechanical properties and translucency ofdifferent yttria-stabilized zirconiaceramics for monolithic dental crown applications, Dent. Mater., 34 (2018), pp. 879-890

29. Ch. Wei, L. Gremillard, The influence of stresses on ageing kinetics of 3Y- and 4Ystabilized zirconia, J. Eur. Ceram. Soc. (2018), pp. 753-760

30. T. Kosmač, A. Kocjan, Ageing of dental zirconia ceramics, J. Eur. Ceram. Soc. (2012), pp. 2613-2622 
31. C. Sanon, J. Chevalier, T. Douillard, M. Cattani-Lorente, S.S. Scherrer, L. Gremillard, A new testing protocol for zirconia dental implants, Dent. Mater., 31 (2015), pp. 15-25

32. J.A. Munoz-Tabares, E. Jimenez-Pique, J. Reyes-Gasga, M. Anglada, Microstructural changes in ground 3Y-TZP and their effect on mechanical properties, Acta Mater., 59 (2011), pp. 6670-6683

33. C.F. Caravaca, Q. Flamant, M. Anglada, L. Gremillard, J. Chevalier, Impact on sandblasting on the mechanical properties and aging resistance of alummina and zircona based ceramics, J. Eur. Ceram. Soc., 38 (2018), pp. 915-925

34. S. Deville, J. Chevalier, L. Gremillard, Influence of surface finish and residual stresses on the ageing sensitivity of biomedical grade zirconia, Biomaterials, 27 (2006), pp. 21862192

35. G.K.R. Pereira, S. Fraga, A.F. Montanager, F.Z.M. Soares, C.J. Kleverlaan, L.F. Valandro, The effect of grinding on the mechanical behavior of Y-TZP ceramics: a systematic review and meta-analyses, J. Mech. Behav. Biomed. Mater. (2016), pp. 417-442

36. T. Douillard, J. Chevalier, A. Descamps-Mandine, I. Warner, Y. Galais, P. Whitaker, J.J. $\mathrm{Wu}, \mathrm{Q} . \mathrm{Q}$. Wang, Comperative ageing behaviour of commercial, unworn and worn 3YTZP and zirconia thoughened alumina hip-joints heads, J. Eur. Ceram. Soc., 32 (2012), pp. $1529-1540$

37. F. Zhang, K. Vanmeensel, M. Inokoshi, M. Batuk, J. Hadermann, B. Van Meerbeek, I. Naert, J. Vleugels, Critical influence of alumina content on the low temperature degradation of 2-3 mol\% yttria-stabilized TZP for dental restorations, J. Eur. Ceram. Soc., 35 (2015), pp. 741-750

38. M. Yoshimura, T. Noma, K. Kawabata, S. Somiya, Role of water on the degradation process of Y-TZP, J. Mater. Sci. Lett., 6 (1987), pp. 465-467

39. J. Chevalier, L. Gremillard, The tetragonal-monoclinic transformation in zirconia:lessons learned and future trends, J. Am. Ceram. Soc. (2009), pp. 1901-1920

40. Y. Wang, Z. Yu, Z. Zhao, L. Jia, H. Fang, T. Zhang, X. Yuan, Y. Shu, J. He, H. Peng, L. Li, J. Zhao, X. Jia, S. Peng, Subchronic toxicity study of yttrium nitrate by 90-day repeated oral exposure in rats, Regul. Toxicol. Pharmacol., 90 (2017), pp. 116-125

41. F. Zhang, M. Inokoshi, K. Vanmeensel, B. Van Meerbeek, I. Naert, J. Vleugels, Lifetime estimation of zirconia ceramics by linear ageing kinetics, Acta Mater., 92 (2015), pp. 290-298

42. J. Chevalier, S. Grandjean, M. Kuntz, G. Pezzotti, On the kinetics and impact of tetragonal to monoclinic transformationin an alumina/zirconia composite for arthroplasty applications, Biomaterials, 30 (2009), pp. 5279-5282 